\title{
Projetos pedagógicos nas escolas comunitárias do Espírito Santo: propostas que se somam à educação do campo
}

\author{
Jorge Luiz de Goes Pereira ${ }^{1}$, Fabrício Darley Paixão Fernandes ${ }^{2}$ \\ ${ }^{1}$ Universidade Federal Rural do Rio de Janeiro - UFRRJ. Departamento de Economia Doméstica/Instituto de \\ Ciências Sociais Aplicadas. BR-465, Km 7, Seropédica, Rio de Janeiro - RJ. Brasil. jolugope@uol.com.br. \\ ${ }^{2}$ Centro Estadual Integral de Educação Rural de Águia Branca-ES
}

RESUMO. A Educação do Campo representa novas possibilidades pedagógicas da educação ofertada nas escolas do campo do Espírito Santo. Este paper discute dois projetos pedagógicos realizados na escola municipal de ensino fundamental Pedra Torta no município de Águia Branca - ES, também denominadas de Escolas Comunitárias Agroecológicas com uma nova ideia de escola com modelo de alternância, fora do eixo das Escolas Famílias Agrícolas e Centros Estaduais Integrados de Educação Rural. Esse modelo de educação visa valorizar a cultura do campo, o cultivo da terra, a qualidade de vida e o equilíbrio harmônico do ambiente. Dentro desse contexto, temos os projetos "Horta Comunitária e Mãos Que Fazem". Trata-se de uma pesquisa qualitativa conduzida através de um estudo de caso, onde foram realizadas observações de campo e análise de documentos relacionados ao desenvolvimento dos projetos pedagógicos no período de 08/4 a 22/06 de 2016. Como resultado, podemos afirmar que essas experiências possibilitam a percepção das diversas dimensões da realidade rural e a valorização da cultura do campo.

Palavras-chave: Projetos Pedagógicos, Educação do Campo, Pedagogia da Alternância. 


\title{
Educational projects in the community schools of the Espírito Santo proposals that add up to rural education
}

\begin{abstract}
The Rural Education represents new pedagogical possibilities of education offered in the rural schools of the Espírito Santo. This paper discusses two educational projects carried out in the municipal elementary school Pedra Torta in the city of Águia Branca - ES, also called Community Schools Agroecology with a new idea of school with switching model, off-axis of the Agricultural Family Schools and Integrated State Centers for Rural Education. This model of education is aimed at valuing the rural culture, the cultivation of land, the quality of life and the harmonious balance of the environment. In this context, we have the project "Horta Comunitária and Mãos Que Fazem". This is a qualitative research conducted through a case study, where was carried out field observations and analysis of documents related to the development of pedagogical projects in the period from $08 / 04$ to $06 / 22$ in 2016. As a result, we can affirm that these experiences enable the perception of the various dimensions of rural reality and valorization of the rural culture.
\end{abstract}

Keywords: Pedagogical Projects, Rural Education, Pedagogy of Alternation. 


\section{Proyectos educativos en las escuelas de la comunidad de las propuestas Espíritu Santo que se suman a la educación rural}

RESUMEN. La educación del campo es nuevas posibilidades pedagógicas de la educación que se ofrece en las escuelas del campo Espírito Santo. Este documento analiza dos proyectos educativos llevados a cabo en la escuela primaria municipal Pedra Torta en la ciudad de Águia Branca - ES, también llamada Comunidad Escuelas Agroecología con una nueva idea de la escuela con el cambio de modelo, fuera del eje de las Escuelas de la Familia Agrícola y Centros de Estado integrado para la Educación Rural. Este modelo de educación está dirigido a incrementar la cultura rural, el cultivo de la tierra, la calidad de vida y el equilibrio armónico del medio ambiente. En este contexto, tenemos el proyecto "Horta Comunitária e Mão Que Fazem". Se trata de una investigación cualitativa a realizada través de un estudio de caso, que se llevó a cabo observaciones de campo y análisis de los documentos relacionados con el desarrollo de proyectos educativos en el período 04/08 a 22/06 en 2016. Como resultado, se puede decir que estas experiencias permiten la percepción de las diversas dimensiones de la realidad rural y valoración de la cultura rural.

Palabras clave: Proyectos Pedagógicos, Educación del Campo, Pedagogía de la Alternancia. 


\section{Introdução}

Desde o período colonial, o Estado do Espírito Santo teve sua economia baseada na produção de café, de mão-deobra familiar e sem recursos técnicos. Essa atividade enfrentou várias crises, como a de 1929 (Rocha \& Morandi, 1991). Na década de 1940, o produto volta a crescer e ganhar importância econômica na balança comercial brasileira, passando a disputar espaço agora como a indústria madeireira. Segundo Rocha e Morandi (1991), dado o caráter capitalista da exploração madeireira, essa atividade altamente dinâmica produtivista se apresenta em contraste com a lenta velocidade da produção familiar.

Assim, a partir da década de 1950, acelera-se o crescimento da exploração madeireira no Espírito Santo, estimulado de um lado pelo aumento do consumo de madeira pela construção civil e setor moveleiro, decorrente do processo de urbanização em curso no país, e do outro, pela política de erradicação do café. Nesse momento, a exploração madeireira emergia como uma das alternativas econômicas à crise. Por outro lado, as legislações que foram criadas pelo Governo do Estado no século XX para disciplinar o desenvolvimento da exploração madeireira, não se mostraram eficazes no controle do desmatamento indiscriminado, causando a destruição do revestimento florístico original.

Outra atividade que merece destaque no processo de desenvolvimento do Estado do Espírito Santo é a pecuária. A pecuária teve extraordinário desenvolvimento como atividade econômica também a partir dos anos 1950. Bergamim (2006) comenta que

a área ocupada por essa cultura apresentou elevados índices de crescimento, sobretudo no norte do estado, onde se encontrava zona pioneira. Nesse sentido, entre 1950 e 1975, segundo os Censos Agropecuários, a taxa de crescimento para o estado foi da ordem de $265 \%$ e para o norte de 681\%. Diversos fatores contribuem para explicar esse elevado crescimento, tais como: a) a erradicação do café, pois a maior parte das terras liberadas pelos cafeeiros foi ocupada pela pecuária; b) o aumento da demanda carne pelo Espírito Santo e estados vizinhos decorrente do processo de urbanização; c) o desgaste dos solos devido ao emprego de técnicas inadequadas tornou algumas áreas impróprias ao cultivo do café, sendo, portanto, ocupadas pela pecuária, e d) o rompimento do ciclo tradicional empregado na agricultura capixaba (p. 11).

Já o município de Águia Branca está localizado na Macrorregião Noroeste, Microrregião Noroeste II, o município de Águia Branca foi criado 1988, e instalado em $1^{\circ}$ de janeiro de 1989. Possui o distritosede, denominado Águia Branca e o distrito de Águas Claras. O Município encontra-se em região de ocorrência da Mata Atlântica, com área de $450 \mathrm{~km}^{2}$. 
Segundo dados do Instituto Brasileiro de Geografia e Economia (IBGE, 2014), o município possui população estimada em 10.055 habitantes, sendo $52 \%$ de homens e $48 \%$ de mulheres, e suas atividades econômicas principais são a produção de café e extração de granitos, e em menor proporção a pecuária de leite e corte. Mas, recentemente, a silvicultura vem ocupando um local de destaque. Já outras culturas, como o coco, vêm tendo suas áreas reduzidas, visto os baixos preços do produto no mercado. $\mathrm{O}$ município apresenta uma das menores taxas de urbanização do Estado, com apenas 24,4\%. Assim, conta com uma população predominantemente rural (em torno de 6.500 pessoas), dispersa em seu território, distribuída em aproximadamente 40 comunidades rurais.

O principal recurso hídrico é o rio São José, que nasce no município de Mantenópolis, percorre o município de Águia Branca numa extensão de aproximadamente $45 \mathrm{~km}$, indo desaguar na Lagoa Juparanã. O rio São José está inserido na Bacia Hidrográfica do Rio Doce que engloba os Estados de Minas Gerais e Espírito Santo (INCAPER, 2013).

Em seu Livro, “Águia Branca - uma rapsódia polonobrasileira na selva capixaba", Altair Malacarne coloca que a miscigenação misturada com os originais caboclos e poloneses gerou um panorama humano especial. Mais tarde, vieram os alemães e, em maior número, os italianos, e todos estes compõem a população atual.

Com a chegada dos pacotes tecnológicos na agricultura nos anos 1990, decorrente da Revolução Verde que influenciou a forma de trabalho, a cultura e a relação socioambiental, impulsionada pela monocultura cafeeira predominante no município de Águia Branca/ES, proporcionando ao longo dos anos uma desvalorização da vida no campo e impacto sobre a fauna e a flora da região (a grande utilização de defensivos agrícolas, por exemplo, levou ao esgotamento das terras produtivas e erosões, o endividamento dos produtores rurais e a precarização das formas de vida no campo). Conforme o Instituto Capixaba de Pesquisa, Assistência Técnica e Extensão Rural (INCAPER, 2013), com o crescimento da cultura do café conilon, plantios de eucalipto e a exploração do granito, as matas da região foram seriamente devastadas, restando hoje apenas alguns remanescentes de Mata Atlântica nos pontos mais elevados e em algumas poucas propriedades.

O INCAPER (2013) afirma ainda que

hoje uma das preocupações tem sido a conservação do solo, procurando envolver $o$ produtor rural na 
discussão e capacitação para o controle da erosão nos solos utilizados. Mas, infelizmente, há diversos casos onde a utilização das terras passa por um processo acelerado de degradação, tornando os solos da região pobres, e condicionando a elevação dos custos de produção com introdução mais insumos externos à propriedade $(\mathrm{s} / \mathrm{n})$.

Essas mudanças proporcionadas pelas atividades econômicas do município trouxeram impactos negativos para a educação, tendo em vista o êxodo rural que se estabeleceu na região, atingindo principalmente os jovens que passaram a não se interessarem pelas atividades rurais, de modo geral.

O modelo pedagógico adotado pelas escolas no meio rural do Espírito Santo era uma educação aos moldes da educação urbana, não havendo uma diferenciação para os moradores do campo, uma educação contextualizada, que levassem em consideração a dinâmica e as identidades rurais no campo. Assim, a forma de ensino no campo não atendia as necessidades e anseios das comunidades rurais inseridas na monocultura do café, desmotivadora da permanência dos jovens no campo, sendo necessário o desenvolvimento de metodologias de ensino nas redes municipais e estaduais do Estado do Espirito Santo direcionadas ao mundo rural.
Nesse contexto, foram criadas as Escolas Famílias Agrícolas e Centros Estaduais Integrados de Educação Rural, com objetivo de valorizar as identidades dos moradores do campo, de diminuir as evasões e reprovações dos estudantes motivando a participação da família e da comunidade no processo educacional através de metodologias alternativas ao modelo tradicional de educação, inserindo, por exemplo, os conceitos e práticas da Agroecologia. Esse é o caso da Escola Comunitária Agroecológica Pedra Torta, na cidade de Águia Branca, de ensino fundamental, que passa a abordar temas e metodologias relacionados com os valores do campo como auxílios pedagógicos, fora do eixo das escolas agrícolas tradicionais de ensino.

A escola municipal de ensino fundamental Pedra Torta foi criada em 2001 como um modelo adequado de educação para região, a qual recebeu, em 2008, projetos sociais idealizados pelo Padre Italiano Domênico Salvador, de inclusão da comunidade para fazer parte da construção do conhecimento, com a criação de projetos como Horta Comunitária e Mãos Que Fazem, cuja visão foi promover uma educação específica, própria e apropriada que pudesse resolver os anseios dos agricultores da região por uma agricultura 
menos impactante sobre o meio ambiente e proporcionando qualidade de vida aos produtores rurais. Sendo uma iniciativa de ensino agrícola fora do eixo das escolas profissionalizantes agrícolas encontradas na região noroeste do Espirito Santo como: Escola Família Agrícola (EFAs) e do Centro Estadual Integrado de Educação Rural (CEIERs). Ambas foram criadas na década de 80 , período caracterizado pelas intensas transformações dos sistemas produtivos familiares, orientadas segundo os moldes da lógica econômica empresarial, ou seja, pela tendência à especialização produtiva por meio de monocultura e utilização de fertilizantes e defensivos agrícolas, o que conduziu ao estreitamento da diversificação de produção, Agroecologia e valorização do homem e da mulher do campo. Foi dentro desse contexto de desestruturação socioeconômico e ambiental que foi implantada a rede de escolas no noroeste do Espírito Santo. Segundo Caldart (2004),

A Educação do Campo se afirma no combate aos 'pacotes' (tanto agrícolas como educacionais) e à tentativa de fazer das pessoas que vivem no campo instrumentos de implantação de modelos que as ignoram ou escravizam. Também se contrapõe à visão estreita de educação como preparação de mãode-obra e a serviço do mercado (p. $5)$.
Atualmente, o Estado do Espirito Santo possui 14 Escolas Famílias Agrícolas (EFAs) associadas ao Movimento de Educação Promocional do Espirito Santo (MEPES) e ainda possuem nove Escolas Famílias Agrícolas não associadas a entidade, além de três escolas agrícolas do estado e o Centro Estadual Integrado de Educação Rural (CEIER), totalizando 26 escolas de ensino agrícola. Os projetos nas escolas no campo possibilitam aos estudantes práticas pedagógicas dentro do seu universo, contribuindo como uma importante ferramenta no desenvolvimento e organização das localidades rurais, através da valorização do saber prático do campo. Essas escolas não contam com um programa de assistência ao estudante institucional, como são as bolsas para sua permanência na escola, elaborado e mantido pelo Estado do Espírito Santo.

Neste contexto, acredita-se que a inserção de projetos pedagógicos voltados para as práticas rurais podem ser ferramentas fundamentais, relacionando teoria e prática no desenvolvimento educacional, como metodologias voltadas para facilitar e proporcionar construções colaborativas que favoreçam a construção de conhecimentos.

O objetivo desse paper é discutir as experiências observadas em dois projetos 
pedagógicos realizados na escola municipal de ensino fundamental Pedra Torta no município de Águia Branca - ES, também denominadas de Escolas Comunitárias Agroecológicas com a proposta de ser uma nova escola no modelo de alternância, fora do eixo das Escolas Famílias Agrícolas e Centros Estaduais Integrados de Educação Rural. Essa escola busca integrar escola-famíliacomunidade dentro do modelo da Pedagogia da Alternância, através de projetos específicos. Assim, temos os projetos Horta Comunitária e Mãos Que Fazem. Esses projetos foram idealizados e mantidos por seu idealizador, o Padre Italiano Domênico Salvador, com apoio da Prefeitura municipal.

São projetos educacionais cuja organização não está articulada com os movimentos sociais, associações de produtores rurais ou qualquer participação popular, mas que demonstram a preocupação e o interesse de uma entidade religiosa em possibilitar transformações necessárias do cenário de desmotivação dos jovens em permanecer no campo, de degradação ambiental e problemas econômicos e sociopolítico no município de Águia Branca, com apoio do poder governamental. Nesse sentido, podemos questionar se mesmo sem uma base ideológica e crítica, esses projetos são capazes de contribuir para a formação cidadã desses alunos e consequentemente das comunidades onde estão inseridos, tendo em vista que esses estudantes estão inseridos num universo de dependência e clientelismo político. Como ressalta o Incaper (2013),

existem 56 associações no município. Apesar de existirem em número bem expressivo e representativo, percebem-se algumas lacunas na sua organização e gestão. Muitas associações têm um histórico ligado ao assistencialismo e "compadrio" político, o que dificulta a realização de um trabalho mais sistemático e organizado em torno dos princípios do associativismo $(\mathrm{s} / \mathrm{n})$.

\section{Metodologia}

Trata-se de uma pesquisa qualitativa, exploratória, onde foi utilizada técnica de estudo de caso. O estudo de caso supõe ser possível conhecer o fenômeno estudado a partir da exploração intensa de um único caso, a partir de uma "análise holística, a mais completa possível, que considera a unidade social estudada como um todo, seja um indivíduo, uma família, uma instituição ou uma comunidade, com o objetivo de compreendê-los em seus próprios termos". (Goldenberg, 2004, p. 33). Segundo Yin (2001), enquanto propósito, os estudos de caso podem ser exploratórios e descritivos. Esse método se mostra muito útil quando o fenômeno a ser 
estudado é amplo e complexo e não pode ser estudado fora do contexto onde ocorre naturalmente.

Para compor nosso estudo de caso, foram realizadas observações e análise dos documentos referentes à constituição da escola e aos projetos Horta Comunitária e Mão Que Fazem. Esse levantamento ocorreu no período de 08 de abril a 22 de junho de 2016.

É importante destacarmos ainda que, devido a não utilização de entrevistas com produtores rurais e seus familiares (os jovens estudantes) e professores da instituição a fim de obtermos suas avaliações sobre o tema tratado, o que buscamos realizar aqui, à luz das premissas ou preceitos da Pedagogia da Alternância, é uma análise interpretativa das observações realizadas no trabalho de campo, durante o processo de implementação dos projetos, se essas observações se articulam com a proposta da Pedagogia da Alternância comumente desenvolvida pelas escolas do campo.

\section{Referencial teórico: uma nova proposta de educação do campo}

A crise na educação das escolas tradicionais é resultado do distanciamento da escola em relação à vida e à cultura de seus sujeitos na sociedade moderna. É o que comumente se observou nas escolas no campo durante muito tempo. Segundo Gramsci (1982), a realidade vivenciada pelos estudantes em suas localidades, de modo geral, deve possuir relação com as atividades pedagógicas desenvolvidas no ambiente escolar, ou seja, devem estar interligadas, caso contrário, não haverá êxito na relação ensino e aprendizagem. Assim, a adoção de novas práticas pedagógicas se relaciona intrinsecamente com as mudanças vivenciadas pelos estudantes de forma dinâmica, atual e propositiva.

O campo não pode ser pensado como lugar de atraso e que os estudantes não necessitem de novos instrumentos ou técnicas de se construir o conhecimento. Mas novas práticas pedagógicas no campo devem ser vividas e percebidas de forma crítica por aqueles que delas fazem uso. Para Caldart, uma educação deve ser No e Do campo:

No: o povo tem direito a ser educado no lugar onde vive; $D o$ : o povo tem direito a uma educação pensada desde o seu lugar e com a sua participação, vinculada à sua cultura e às suas necessidades humanas $\mathrm{e}$ sociais (Caldart, 2002, p. 18).

Essas ações acontecendo promovem a relação harmônica entre o Ser Humano e a Natureza. Além disso, "um ensino contextualizado na realidade contemporânea e que instrumentalize o educando para uma reflexão crítica na 
leitura da realidade onde se insere, inclui métodos e práticas de ensinoaprendizagem que sejam inovadores". (Dremiski \& Valadão, 2012, p. 137).

No desenvolvimento dos projetos educativos é fator indissociável a existência de uma liderança clara que harmonize os objetivos organizacionais com a pluralidade de interesses em presença e que permita responder com a eficácia desejável aos desafios progressivamente mais complexos feitos às escolas. As escolas não podem ser consideradas fora do contexto da realidade do local onde estão inseridas, ou seja, sua comunidade, circunstância que concorre para que se possa afirmar que "a escola é um contexto". (Batanaz, 2003, p. 114). A esse respeito, Almeida (2002) acrescenta:

o projeto rompe com as fronteiras disciplinares, tornando-as permeáveis na ação de articular diferentes áreas de conhecimento, mobilizadas na investigação de problemáticas e situações da realidade. Isso não significa abandonar as disciplinas, mas integrá-las no desenvolvimento das investigações, aprofundando-as verticalmente em sua própria identidade, ao mesmo tempo, que estabelecem articulações horizontais numa relação de reciprocidade entre elas, a qual tem como pano de fundo a unicidade do conhecimento em construção (p. 58).

Portanto, as experiências com projetos pedagógicos contextualizados são possibilidades de novas práticas educativas de formação do sujeito, onde o vivido se soma ao apreendido na escola. Assim como nos espaços urbanos, os jovens que vivem, trabalham e estudam no campo têm direito a conhecimentos e práticas inovadoras, uma pedagogia que leve em consideração as especificidades de cada território, as diferentes identidades sociais observadas no mundo rural. Nesse sentido, projetos pedagógicos nas comunidades atendidas pela escola, representam oportunidades de construção de novas formas de educação no campo.

\section{A Escola Municipal de Ensino Fundamental Pedra Torta}

As escolas de ensino agrícolas começaram a se intensificar na década de 60 no Espirito Santo, influenciadas diretamente pelas experiências e sucessos das Maison Familiale Rurale (MFRs), na França pelos Padres Jesuítas. No Brasil, esse período foi caracterizado pelas intensas transformações dos sistemas produtivos e socioeconômico, orientadas segundo os moldes da lógica econômica empresarial, ou seja, pela tendência à especialização produtiva por meio de monocultivos, o que conduziu ao estreitamento da diversidade de produção, desvalorização da agricultura familiar e êxodo rural (Zamberlan, 1995). 
Diante desse cenário, foram criadas as Escolas Agrícolas, buscando uma educação ligada aos valores da vida no campo, à cultura, ao trabalho, à política e à cidadania, se fez necessário surgimento de escolas com práticas pedagógicas nas escolas localizadas no campo.

A criação de uma escola no campo, pensada para o desenvolvimento sustentável das comunidades inseridas na região, para que efetivamente sintam-se cidadãos pertencentes ao ambiente escolar, tornou-se parte da construção do conhecimento de crianças e jovens do campo. A Escola Pedra Torta iniciou suas atividades em janeiro 2001, a pedido e pressão dos moradores da localidade do Córrego de Pedra Torta sob a justificativa de ainda não possuíam uma escola comunitária que atendesse as suas necessidades, inserida na zona rural, município de Águia Branca, localizada a $14 \mathrm{~km}$ de distância do centro da cidade. A escola Pedra Torta é municipal de ensino fundamental, porém trabalha com os princípios da Pedagogia da Alternância e das escolas famílias agrícolas em seus projetos pedagógicos.

A escola atualmente possui 170 estudantes, que desenvolvem dois projetos junto às comunidades e com participação de outras escolas municipais. São eles: Projeto Horta Comunitária e o projeto social Mãos Que Fazem, que surgiram para contribuir com os estudantes de localidades carentes de infraestrutura e condições sociais, que participavam de oficinas de artesanatos como: pintura em tecidos, biscuit, bordados em chinelos, fabricação de ovo de páscoa, marcas em tecidos, fabricação de almofadas e travesseiros. As crianças assistidas recebiam uma ajuda de custo, mantidas pelo próprio Padre D. Salvador e seus amigos da Itália, onde cada amigo se prontificou a escolher uma ou mais famílias para ser um padrinho, ou seja, uma espécie de (apadrinhamento), e também ajuda para promover palestras, oficinas e aprenderem na prática as principais formas de manejo de hortaliças como: plantio em bandejas, replantio nos canteiros, adubação orgânica e controle alternativo de pragas e doenças. Além disso, são constantemente visitadas pelos professores e recebem orientação sobre saúde e qualidade de vida.

Essas atividades podem ser consideradas assistencialistas na base, contudo, passaram a cumprir um papel fundamental na localidade devido ao descaso das autoridades públicas, tendo que contar com a instituição religiosa e seus devotos. Elas representaram as únicas possibilidades de acesso a algum tipo de formação e ajuda financeira para a reprodução social das famílias envolvidas 
em Águia Branca, pois a escola não conta com um programa governamental de assistência ao estudante, na forma de bolsas para sua permanência na escola. Elas não tinham a intenção de se tornarem oportunidades de aprendizagem crítica, mas apenas, dentro de um contexto religioso, darem acesso à educação àqueles à margem das políticas públicas.

\section{Os Projetos Horta Comunitária e Mãos Que Fazem: experiências em debate}

É importante destacarmos que para que a implantação de um projeto agroecológico se concretize em uma região, deve haver o mesmo consenso ideológico de todos os setores envolvidos, seja esse de pessoas, de instituições públicas ou privadas e de leis que garantam o desenvolvimento sustentável, na proteção dos recursos naturais, na aquisição de renda, na segurança alimentar. Não visando apenas o desenvolvimento econômico através da agricultura, mas também o desenvolvimento social e cultural da comunidade. Assim, mesmo que indiretamente, as propostas apresentadas pela Escola encontraram ressonância nas premissas mais amplas da educação nas premissas da Agroecologia.

No caso observado, os projetos pedagógicos possuíam importância significativa, pois através de seus resultados podem se fazer diagnósticos concretos da realidade vivenciada pela escola, pela família e pelas comunidades de maneira significativa, mesmo que indiretamente. Isso é importante ressaltar aqui, pois a não articulação desses projetos desenvolvidos pela escola com movimentos sociais ou associações está diretamente ligada ao fato das características culturais do município: relações de dependência e compadrio com os políticos locais. Por outro lado, eles podem contribuir para novas reflexões e levantamento de problemas que devem ser compartilhados com outras pessoas, a fim de encontrar meios para resolvê-los de forma crítica e participativa. Assim, produz-se conhecimentos. Essa perspectiva é reforçada por Caldart (2003), quando afirma que
ajudar a construir escolas do campo é, fundamentalmente, ajudar a constituir os povos do campo como sujeitos, organizados e em movimento. Porque não há escolas do campo sem a formação dos sujeitos sociais do campo, que assumem e lutam por esta identidade e por um projeto de futuro. Somente as escolas construídas política e pedagogicamente pelos sujeitos do campo conseguem ter o jeito do campo, e incorporar neste jeito as formas de organização e de trabalho dos povos do campo (p. 66).

Os Projetos Horta Comunitária e Mãos Que Fazem começaram a serem pensados a partir de problemáticas sociais 
e financeiras observadas por professores, pedagogos e por alguns estudantes de alternância. A primeira etapa foi um estudo mais aprofundado da realidade no cotidiano da família e da comunidade desses estudantes, ao qual permitiu identificar as reais necessidades vivenciadas pelos mesmos. Em seguida, foram realizadas as propostas de encaminhamentos coletivos ao corpo administrativo escolar, ao qual garantiram a participação na organização dos trabalhos. A segunda etapa foi encaminhar um relatório dos resultados da pesquisa ao Padre D. Salvador, o qual já tinha projetos sociais, educacionais e agroecológicos de sucesso, em destaque a "Fazenda Lacerda", referência na produção de hortaliças orgânicas e artesanato na região. A terceira etapa foi a realização de uma audiência com a prefeitura municipal, solicitando parceria na realização e implantação dos projetos pedagógicos na escola municipal Pedra Torta.

Neste caso, não se pode afirmar que a proposta veio de cima para baixo e apenas de forma assistencialista. Ela estava inserida num debate mais amplo da comunidade, da escola e da prefeitura. A escolha dos projetos foi realizada de forma democrática, portanto, a escola cumpriu um papel fundamental na sua implantação, e, sucessivamente, os estudantes tiveram uma experiência política e crítica na discussão de elaboração e de execução dos projetos. A implantação desses projetos teve como objetivo melhorar o processo ensino-aprendizagem, através de atividades que fazem parte da realidade socioeconômica da comunidade na qual a escola está inserida, consequentemente, contribuir para a melhoria da qualidade de vida dos estudantes e suas famílias.

O projeto Horta Comunitária iniciou com a escolha de uma área inutilizada da escola, na qual foram construídos canteiros para produção orgânica de hortaliças, proporcionando motivação e participação com práticas de campo realizadas pelos estudantes. Nesse projeto, todos participaram, num total de 170 estudantes, que desenvolveram atividades como: construções de canteiros, semeadura, plantio, cuidados diários de manejo e colheita.

As hortaliças foram consumidas na própria escola e os excedentes de produção levados para a casa dos estudantes, instigando o diálogo entre os estudantes e seus pais, cujo objetivo foi a motivação dos estudantes para a futura implantação da horta caseira. Construiu-se assim uma relação dialógica entre teoria e prática, além de reforçar a identidade desses estudantes com o mundo rural, o convívio 
familiar, as práticas sustentáveis e seu papel político.

O projeto da Horta Comunitária enfatizou a importância de uma alimentação saudável, além de motivá-los a desenvolver uma horta em casa, servindo de palco para o aprimoramento de saberes através da interdisciplinaridade entre as disciplinas de ensino fundamental $\mathrm{e}$ as aulas práticas na área de olericultura da escola. Por sua vez, entende-se que as hortas comunitárias não funcionam apenas como uma ferramenta de ensino aprendizagem para as escolas, mas também trazem discussões sobre as questões socioambientais, o trabalho em mutirões e os bons hábitos culturais e alimentares que foram se perdendo ao longo do tempo no meio rural (Muniz \& Carvalho, 2007).

A implantação da horta ocorreu na primeira etapa com oficinas e palestras sobre a valorização do homem e da mulher do campo, do cultivo da terra, da qualidade de vida, do equilíbrio harmônico do ambiente, de motivação para explicar como devem ser implantados os canteiros de hortaliças e a importância da horta orgânica em casa. Na segunda etapa, foram distribuídas sementes de diferentes cultivares para que os estudantes iniciassem o plantio. $\mathrm{Na}$ terceira etapa, a comunidade participou de um campeonato para escolha da melhor horta caseira construída, com premiação aos três primeiros colocados, envolvendo e fortalecendo o elo entre escola, família e comunidade.

O interessante a destacar aqui é que a escola, apesar de estar localizada no campo, não é uma escola tradicionalmente de ensino agrícola, não possui disciplinas ligadas à agricultura em sua grade curricular. No entanto, a escola promoveu, juntamente com o apoio da prefeitura, cursos e palestras sobre meio ambiente, preservação e conservação de nascentes, produção orgânica de hortaliças e frutíferas, oficinas de artesanatos e cursos básicos de informática para os familiares dos estudantes e outros moradores locais.

Já o projeto Mãos Que Fazem, outro projeto socioeconômico dentro da escola, de fabricação de artesanato, surgiu em 2008, com a finalidade de contribuir com os estudantes com necessidades financeiras na família. O projeto envolveu estudantes do ensino fundamental com histórico de dificuldades financeiras, na sua maioria, filhos de agricultores que não possuem propriedades agrícolas, trabalham na propriedade de terceiros ou alugam a terra para cultivar, onde todo o lucro da produção é dividido com o dono da terra, regime de trabalho chamado na região de "meeiros", nos quais, por sua vez, não possuem renda econômica satisfatória, 
capaz de responder as necessidades de alimentação e outros custeios de suas famílias. Foram atendidos 22 estudantes que se enquadraram no perfil da bolsa para receberem a ajuda de custo. Somam-se a bolsa recebida, os recursos recebidos com as vendas dos artesanatos construídos nas oficinas como: pintura em tecidos (panos de prato), bordados em chinelos, brolhas e vagonites, almofadas, marcas em pano xadrez e ovos de páscoa.

Essas experiências demonstram que a elaboração de projetos pedagógicos, que retratam a realidade vivenciada pelos estudantes do meio rural, contribui como importante ferramenta de integração do conhecimento, além de contribuir para a melhoria da sua qualidade de vida e de seus familiares. Elas possibilitam um maior entendimento da dinâmica entre teoria e prática dentro e fora da escola. Além disso, contribuem para um maior sentimento de pertencimento ao espaço vivido, do papel político a ser desenvolvido. Pequenas experiências como essas são capazes de transformar a relação do sujeito com o mundo. Como afirma Veiga (2003),

introduzir inovação tem o sentido de provocar mudança, no sistema educacional. De certa forma, a palavra 'inovação' vem associada a mudança, reforma, novidade. $\mathrm{O}$ 'novo' só adquire sentido a partir do momento em que ele entra em relação com o já existente (p. 270).
Portanto, os projetos experienciados pelos estudantes foram fundamentais para o seu reconhecimento como homem e mulher do campo, pois eles estão diretamente ligados à reprodução de sua identidade social e permanência no lugar de origem. Evita-se, desta forma, uma das mais perversas características que atingem os jovens rurais, que é o êxodo. Os jovens que se reconhecem como rurais, têm maior autoestima quando veem sua identidade valorizada pela escola e refletida no lugar onde vivem.

\section{Modelo de alternância desenvolvido na Escola Fundamental de Pedra Torta}

A metodologia adotada nos projetos realizados na escola de Pedra Torta, segundo seus representantes, é a da Pedagogia da Alternância. Segundo Lima (2012),

\begin{abstract}
A Pedagogia da Alternância é uma proposta teórica metodológica distinta da educação convencional, pois permite ao educando ter uma visão específica da sua realidade através dos conhecimentos teóricos absorvidos na sala de aula e situá-los na integralidade de sua vivência pessoal, social, ambiental e econômica (p. 46-60).
\end{abstract}

Alternância significa o processo de ensino-aprendizagem que acontece em espaços e territórios diferenciados e alternados. O primeiro é o espaço familiar e a comunidade de origem (realidade); em 
segundo, a escola onde o educando partilha os diversos saberes que possui com os outros atores e reflete-se sobre eles em bases científicas (reflexão); e, por fim, retorna-se a família e a comunidade a fim de continuar a práxis (prática + teoria) seja na comunidade, na propriedade (atividades de técnicas agrícolas) ou na inserção em determinados movimentos sociais. Como ressalta Jesus (2010),

\begin{abstract}
A alternância ajuda o estudante a conhecer e valorizar o seu modo de vida, a cultura local e despertar a consciência crítica, ampliando seus conhecimentos. A escola é espaço da reflexão teórica e de aprofundamentos das questões relevantes de interesses dos alunos e das famílias. $O$ tempo de permanência do aluno no espaço familiar e na comunidade é o momento para confrontar a teoria com a prática, pesquisar, realizar experimentação de novas práticas, troca de experiências, trabalho e indagações. Ou seja, desse ponto de vista, a formação na alternância é contínua (p. 9).
\end{abstract}

Tivemos a oportunidade de verificar que a metodologia de ensino em alternância adotada e executada pela escola Pedra Torta nos projetos possui similaridade aos das Escolas Famílias Agrícolas (EFA), a qual o Pe. Domênico Salvador já possui bastante experiência com a metodologia de trabalho desde a Itália. Quando se juntou as experiências dos projetos pedagógicos de Pedra Torta com a Pedagogia da Alternância, os resultados mais positivos apareceram no ensino aprendizagem, funcionando no $1^{\circ}$ tempo a experiência de vida durante as estadias em casa, $2^{\circ}$ tempo suas reflexões na escola durante as aulas.

Partimos do pressuposto de que o projeto pedagógico que não reflete $\mathrm{o}$ cotidiano rural corta o processo de aprendizagem e desanima os estudantes. É a primeira tomada de consciência da realidade do próprio aluno. No caso da Escola de Pedra Torta, as crianças e jovens alternam sessões educativas na família/Comunidade e na Escola. A alternância se dá de forma integrada onde o trabalho e o estudo são dois momentos interligados porque em ambos os momentos se aprende e se interage.

As experiências com Pedagogia da Alternância no meio rural são variadas, podemos afirmar que são até distintas. Isso pode ser verificado, principalmente na carga horária direcionada ao Tempo Escola e ao Tempo Comunidade. No caso de Pedra Torta, os estudantes vão à escola todos os dias durante a semana, porém ocorre uma alternância nas cargas horárias: durante uma semana ficam na escola em tempo integral, ou seja, oito horas por dia; na outra semana, ficam quatro horas do tempo integral direcionados para as atividades extracurriculares dos projetos em curso. Contudo, a execução dos 
projetos Horta Comunitária e Mãos Que Fazem da escola só foram possíveis devido à utilização da Pedagogia da Alternância como metodologia de ensino e aprendizagem, isto é, parte do tempo dos projetos foi desenvolvida junto a seus familiares, em suas propriedades.

\section{O envolvimento da família e da comunidade na escola}

Ao se pensar em educação escolar como um todo, e não só no meio rural, é preciso ter em mente que a participação da família nesse processo deve ser harmônica e continua na vida escolar dos estudantes em todos os sentidos, ou seja, é preciso que haja uma integração plena entre escola, família e comunidade, pois serão nessas três bases que os estudantes formarão opinião ética, social, cultural e ambiental.

A participação da família e da comunidade em projetos de desenvolvimento local proporciona um ambiente favorável à expansão do envolvimento do ensino e da aprendizagem dos estudantes. As ações participativas da família dentro dos projetos pedagógicos da escola, como os exemplos anteriormente descritos, facilitam a inclusão do coletivo em todas as etapas de elaboração, favorecendo e estimulando a agricultura familiar, buscando incorporar novas culturas economicamente viáveis e ecologicamente corretas para região, procurando diminuir o êxodo do campo para as cidades e da região para outras regiões.

No caso da escola observada, isso é de fundamental importância tendo em vista o processo histórico de movimentos migratórios no estado do Espírito Santo. Os dados do documento Movimentos Migratórios no estado do Espírito Santo 1986-1991 (COET/IPES, 2003) informam que a Taxa de Imigração (TI) foi de 5,89\%, a Taxa de Emigração (TE) de 3,75\% e a Taxa de Migração Interna (TMI) de 9,91\%, no período analisado. Esses dados chamam a atenção para $o$ fato de haver um movimento interno de mudanças de locais de moradias no estado, ao invés da saída dos capixabas para aquelas regiões que até então apresentam melhores taxas de desenvolvimento econômico, como é o caso de Rio de Janeiro e São Paulo. Segundo o documento, um dos principais motivos foi o processo de industrialização de algumas cidades capixabas, Microrregiões Metropolitanas, principalmente as de porte médio a partir da década de 90.

Ainda, segundo o documento da COET/IPES (2003), a microrregião Noroeste II, onde se localiza o município de Águia Branca, está entre as menos atraentes no Estado dentro do período 
analisado (1986-1991): Noroeste II $(1,82 \%)$, Sudoeste Serrana (1,82\%) e Central Serrana (0,96\%). Dentre os municípios do estado, o de Serra foi o maior receptor de imigrantes, abrigando $17,16 \%$ do total, seguido por Vila Velha e Vitória, que ficaram com 12,77\% e $12,56 \%$, respectivamente, e Cariacica, com 10,37\%. No total, o Estado recebeu 135.972 pessoas, sendo o município de Água Branca um dos que recebeu menor interesse desse movimento, apenas 196 pessoas $(0,14 \%)$. Os dados revelam ainda que o processo de saída do município foi maior que o de entrada: $683(2,67 \%)$ do total de 25.572 pessoas.

Esse processo revela, na verdade, que desde a década de 1980, os espaços constituídos pelas atividades de monocultura do café, produção madeireira e extração de granitos, se tornaram menos atraentes para aqueles que vivem da agricultura familiar ou do trabalho assalariado na agricultura extensiva. Não precisamos enfatizar aqui que os processos de êxodo rural no Brasil atingiram preferencialmente os jovens, pelo fato de estarem num momento de vida onde suas incertezas quanto ao futuro são ainda maiores porque dependem dos pais, familiares e de outras pessoas que possam ampliar seu campo de possibilidade para a realização de seus projetos de vida (Pereira, 2008).

As famílias que são atendidas pelos projetos são famílias dos alunos do $6^{\circ}$ a $9^{\circ}$ ano, que vivem nas comunidades em torno da escola, nas comunidades do Córrego da Pedra Torta, Pedra Bonita, Beija-Flor, Aparecidinha, Parado, Macuco e Ebenezer. Ao todo são atendidas 130 famílias. Essas famílias têm como característica a produção cafeeira em pequenas áreas de cultivos, sendo a atividade que mais contribui para os recursos financeiros do grupo familiar.

O ensino proporcionado pela escola para essas famílias é baseado na metodologia das Escolas Famílias Agrícola, ou seja, educação própria e apropriada para o homem e a mulher do campo. Como afirma Speyer (1983),

assim também o objetivo final da educação não é o desenvolvimento da ciência e da tecnologia - é a relação do homem como pessoa humana e que transcende o objetivo final desses conhecimentos e supõe o despertar da espontaneidade vital do educando e o alargamento constante de sua opinião (p. 77).

Como foi dito anteriormente, dentro do projeto Mãos Que Fazem, a família dos estudantes carentes tem atenção especial, onde recebem uma bolsa de ajuda financeira do Padre e Amigos Italianos. Cada professor da escola fica responsável em visitar um grupo de famílias para 
observar as realidades vivenciadas pelos seus estudantes.

Observamos que a presença da escola junto às comunidades possibilita a participação direta dos pais na vida escolar de seus filhos, de forma a integrar as famílias no universo escolar e para que a escola possa conhecer e entender a realidade vivenciada pelos seus alunos, criando possibilidade de compartilhar critérios educativos de intervenção de forma harmônica.

Segundo Libâneo, Oliveira e Toschi (2003), as atividades que contemplam a relação escola/comunidade implicam em ações

que envolvem a escola e suas relações externas, tais como os níveis superiores de gestão do sistema escolar, os pais, as organizações políticas e comunitárias, as cidades e os equipamentos urbanos. O objetivo dessas atividades é buscar as possibilidades de cooperação e de apoio, oferecidas pelas diferentes instituições, que contribuam para o aprimoramento do trabalho da escola, isto é, para as atividades de ensino e de educação dos alunos. Espera-se especialmente, que os pais atuam na gestão escolar mediante canais de participação bem definidos (p. 348349).

Para que ocorra a participação da família e da comunidade, a escola tem que se adequar as necessidades de disponibilidade de tempo de ambas as partes, tanto da escola como das famílias, sendo isso uma tarefa nada fácil, muito menos simples, exige a disposição do conjunto dos atores, além de energia, trabalho e, sobretudo, tempo. É um processo construtivo e interativo entre os diferentes atores sociais envolvidos na construção do conhecimento e na transformação da realidade. Essa dinâmica produz como resultado um projeto comum e harmônico, minimizando as possíveis diferenças entre os dois ambientes: escola e família. Sem dúvida que essa participação entre esses dois ambientes traz inúmeras vantagens, principalmente no aspecto social com forte interferência no aprendizado e na motivação dos estudantes.

\section{Considerações finais}

Nos últimos anos, a contribuição de projetos pedagógicos direcionados à dinâmica do mundo rural vem demonstrando resultados positivos, pois diminui consideravelmente a evasão e a reprovação escolar, ao mesmo tempo que fortalece a identidade social dos grupos rurais. Estes projetos estão voltados a melhoraria da qualidade do ensino no campo, favorecendo a produção agrícola para que seja diversificada, qualificada e incentivando o desenvolvimento humano, ecológico, econômico e social para se viver no campo com dignidade. 
Os projetos aqui relatados não têm fim em si mesmo e são potencializados pela Pedagogia da Alternância, trazendo novos significados para o processo de aprendizagem dos alunos, principalmente no que tange a sua atuação política e econômica junto às suas famílias. Eles foram elaborados a partir das necessidades, limitações e potencialidades das comunidades envolvidas, dos alunos, da equipe escolar, além de levar em conta os recursos pedagógicos e materiais existentes na escola. No decorrer do trabalho de pesquisa houve momentos em que as famílias e as comunidades participaram dos eventos ocorridos na escola, porém é fato que essa participação passou a ser mais dinâmica e atrativa no decorrer das atividades desenvolvidas nos projetos. Assim, elas ajudam aproximar o universo da casa, da família, da organização da produção agrícola, do universo escolar e da atuação crítica dos alunos. Nesse sentido, podemos falar de uma simbiose de interesses.

Não adianta se temos uma escola no campo fisicamente bem estruturada, possibilitando um bem-estar do estudante, se não houver projetos que de fato integrem os dois universos: família, comunidade e escola. Foi observada, além da diminuição da evasão escolar e das reprovações, uma maior participação dos pais no ambiente escolar a partir da implantação dos projetos pedagógicos, concretizando a formação de cidadãos conscientes de seu papel na comunidade, fornecendo ao aluno, ainda, subsídios necessários à sua melhor inclusão social, cultural e econômico. Esse esforço tem contribuído para fortalecer os processos educacionais e permite que os mesmos extrapolem o âmbito da escola e se amplie a vida em direção ao trabalho, à formação humana.

Nesse sentido, as experiências reveladas com esses projetos apontam para uma diferenciação da Escola Pedra Torta na utilização da Pedagogia da Alternância, pois, mesmo que sem uma interação com os movimentos sociais ou organizações populares, associações de produtores rurais, e sem a participação mais efetiva do poder municipal, com programas institucionais de bolsas de custeio ou qualquer forma mais ativa e atrativa para favorecer a permanência dos jovens no campo, essa Escola vem possibilitando aos seus estudantes a valorização da sua identidade social.

\section{Referências}

Almeida, M. E. B. (2002). Educação, projetos, tecnologia e conhecimento. São Paulo: PROEM.

Batanaz, P. L. (2003). Organizações Escolares. Bases Científicas 
Desenvolvimento das instituições educativas. Córdoba: Universidade de Córdoba.

Bergamim, M. C. (2006). A Pequena Propriedade Rural no Espírito Santo: constituição e crise de uma agricultura familiar. $44^{\circ}$ Congresso da Sociedade Brasileira de Economia, Administração e Sociologia Rural (SOBER). Fortaleza. Recuperado em 08 de dezembro, 2016, em http://www.sober.org.br/palestra/5/952.pdf

Caldart, R. S. (2004). Pedagogia do Movimento Sem Terra. São Paulo: Expressão Popular.

(2003). A escola do campo em movimento. Currículo sem Fronteiras, (3), 60-81.

(2002). Por uma Educação do Campo: traços de uma identidade em construção. In Educação do Campo: identidade e políticas públicas. Brasília: DF.

COET/IPIS. (2003). Movimentos Migratórios no Estado do Espírito Santo 1986-1991. Espírito Santo/Vitória. Recuperado em 07 de dezembro, 2016, em file://C:/Users/jolug/Desktop/20120829_ movimentosmigratoriosdoes 1986 1991.p df

Dremiski, J. L., \& Valadão, A. C. (2012). Comunicação Rural e Organização social no Campo. Instituto Federal do Paraná Educação à Distância.

Goldenberg, M. (2004). A arte de pesquisar: como fazer pesquisa qualitativa em Ciências Sociais. Rio de Janeiro: Record.

Gramsci, A. (1982). Os intelectuais e a organização da cultura. Rio de Janeiro: Civilização Brasileira.
Instituto Brasileiro de Geografia e Estatística. (2014). Censo Demográfico.

Instituto Capixaba de Pesquisa, Assistência Técnica e Extensão Rural. (2013). Programa de Assistência Técnica e Extensão Rural PROATER 2011 - 2013.

Jesus, J. N. (2010). A pedagogia da alternância e o debate da educação no/do campo no estado de Goiás. Revista Nera. 14(18).

Libâneo, J. C., Oliveira, J. F., \& Toschi, M. S. (2003). Educação Escolar: políticas, estrutura e organização. São Paulo: Cortez.

Lima, A. V. (2012). Educação do campo e Pedagogia da Alternância: algumas considerações metodológicas. In Entrelaçando: Revista Eletrônica de Culturas e Educação, 6(2), 46-60.

Muniz, V. M., \& Carvalho, A. T. (2007). O Programa Nacional de Alimentação Escolar em município do estado da Paraíba: um estudo sob o olhar dos beneficiários do Programa. Revista de Nutrição, 20(3), 285-296.

Pereira, J. L. G. (2008). Educação, gênero e os projetos de vida dos jovens rurais de Baixada de Salinas (RJ). Revista Ruris, 2(2), 71-97.

Rocha, H. C., \& Morandi, A. M. (1991). Cafeicultura e grande indústria: a transição no Espírito Santo 1955-1985. Vitória: Fundação Ceciliano Abel de Almeida.

Speyer, A. M. (1983). Educação $e$ campesinato: Uma educação para o homem do meio rural. São Paulo: Edições Loyola.

Veiga, I. P. A. (2003). Inovações e projeto político-pedagógico: uma relação regulatória ou emancipatória? Caderno CEDES, 23(61), 267-281. 
Yin, R. K. (2001). Estudo de caso: planejamento e métodos. Porto Alegre: Bookman.

Zamberlan, S. (1995). Pedagogia da Alternância. Piúma: ES. MEPES.

Recebido em: 03/10/2016

Aprovado em: 21/11/2016

Publicado em: 19/04/2017

Como citar este artigo / How to cite this article / Como citar este artículo:

APA:

Pereira, J. L. G., \& Fernandes, F. D. P. (2017). Projetos pedagógicos nas escolas comunitárias do Espírito Santo: propostas que se somam a educação do campo. Rev. Bras. Educ. Camp., 2(1), 23-44.

ABNT:

PEREIRA, J. L G.; FERNANDES, F. D. P. Projetos pedagógicos nas escolas comunitárias do Espírito Santo: propostas que se somam a educação do campo. Rev. Bras. Educ. Camp., Tocantinópolis, v. 2, n. 1, p. 23-44, 2017. 